\title{
Should Eligibility for Medication Therapy Management Be Based on Drug Adherence?
}

\author{
Bruce Stuart, PhD; F. Ellen Loh, MBA, BSPharm; Laura Miller, PhD; and Pamela Roberto, MPP
}

\begin{abstract}
BACKGROUND: Medicare Part D prescription drug plans must offer medication therapy management (MTM) services to qualified enrollees. Eligibility criteria used by plan sponsors are restrictive, and fewer than $10 \%$ of Part $D$ enrollees receive MTM services. The extent to which plan criteria identify beneficiaries most at risk for suboptimal medication use is unknown.

OBJECTIVES: To (a) evaluate potential underuse of and poor adherence to evidence-based medications used in the treatment of Medicare beneficiaries with diabetes, heart failure, and chronic obstructive pulmonary disease (COPD) over 3 years; (b) determine whether MTM eligibility criteria used by the modal Part D plan in 2011 (drug spending $\geq \$ 3,000, \geq 3$ chronic conditions, $\geq 8$ Part $D$ medications) identified Part D enrollees at greatest risk for underuse of and poor adherence to these drugs; and (c) demonstrate how sensitive MTM eligibility is to variations in criteria levels.
\end{abstract}

METHODS: Study subjects were selected from a $5 \%$ random sample of Part D enrollees with 1 or more of these diseases in 2006 and followed through 2008 or death. Longitudinal patterns of exposure and adherence to angiotensin-converting-enzyme inhibitor/angiotensin receptor blockers, beta-blockers, and COPD controller drugs were tracked comparing patterns for enrollees meeting/not meeting the modal 2011 MTM eligibility criteria.

RESULTS: Use of evidence-based medication was consistently suboptimal for every disease cohort studied. Higher rates of exposure and adherence were observed among those with high drug spending taking multiple Part D drugs. Current MTM criteria were found to target beneficiaries with above average utilization of evidence-based medication and to exclude those with more problematic utilization patterns. We estimate that lowering the maximum required drug count from 8 to 2 would increase the percentage of beneficiaries eligible for MTM by two thirds.

CONCLUSIONS: Our findings suggest that MTM eligibility criteria are not optimally targeted to capture underuse of and poor adherence to evidencebased medications. Policymakers should weigh the pros and cons of loosening restrictive MTM eligibility criteria to target patients with potentially greater needs.

\section{J Manag Care Pharm. 2014;20(1):66-75}

Copyright @ 2014, Academy of Managed Care Pharmacy. All rights reserved.

\section{What is already known about this subject}

- According to clinical practice guidelines, most elderly patients with diabetes should be taking an angiotensin-converting enzyme inhibitor or angiotensin receptor blocker for hypertension control and prevention of kidney disease. Similarly, patients with heart failure should be prescribed beta-blockers, and chronic obstructive pulmonary disease (COPD) patients should take controller medications to prevent acute exacerbations of the disease. Studies have shown that adherence to these drugs tends to be suboptimal in conventional practice.
- Almost all Part D plans target diabetes and heart failure as conditions eligible for medication therapy management (MTM) review, and more than half of plans target COPD.

- The effectiveness of MTM interventions has been demonstrated in small focused studies primarily restricted to non-Medicare beneficiaries.

\section{What this study adds}

- MTM programs targeted to Part D enrollees with high drug spending, multiple comorbidities, and multiple Part D medications miss many individuals who fail to take evidence-based medications or exhibit poor adherence to them.

- Part D plans can better target enrollees with poor adherence by lowering the number of drugs required for MTM review. We estimate that lowering the maximum required drug count from 8 to 2 would increase the percentage of beneficiaries eligible for MTM eligibility by two thirds.

- Because many chronic medications are intended to be taken over a lifetime, it is important for MTM programs to monitor Part D enrollees' drug utilization patterns over several years.

$\mathrm{M}$ edicare Part D prescription drug plans must offer medication therapy management (MTM) services to qualified enrollees. The purpose of MTM is to promote appropriate use of medicines and to optimize therapeutic outcomes through a combination of patient education, prescriber interventions, and referrals for specialized services such as disease management. Centers for Medicare \& Medicaid (CMS) regulations require that all Part D beneficiaries enrolled in an MTM program receive an annual comprehensive personto-person medication review followed by quarterly updates, interventions with prescribers where warranted, and a written summary of recommendations.

The literature on MTM effectiveness is sparse, particularly for Part D MTM programs. Several studies have shown MTM to be effective in non-Medicare settings. ${ }^{1-5}$ A study conducted by Hirsch et al. (2011) $)^{1}$ reported significant improvement in medication adherence. Ramalho de Oliveira et al. (2010) ${ }^{2}$ and Barnett et al. (2009) $)^{3}$ demonstrated that MTM programs can reduce drug costs. Moore et al. (2013) ${ }^{4}$ showed that MTM programs can both improve drug adherence and produce cost savings. However, this evidence may not translate directly to 
Medicare MTM programs given differences in eligibility criteria and intervention strategies. A few published case studies of Medicare MTM performance report limited improvements in medication regimens, but the results are not generalizable to the Medicare population at large..$^{6-9}$

To meet minimum MTM eligibility criteria for 2013, beneficiaries must have projected annual drug spending of at least $\$ 3,144,2$ or 3 specific chronic conditions, and be taking a minimum of 2 to 8 different Part D drugs. ${ }^{10}$ Although some Part D plans offer MTM services to their entire membership, plans typically select eligibility criteria that result in relatively few enrollees being targeted. CMS reports that the percentage of Part D enrollees receiving MTM nationwide actually declined from $11 \%$ in 2008 to $9.1 \%$ in $2010 .{ }^{11}$ As a result, many beneficiaries who might benefit from MTM are denied the opportunity. With such narrow targeting, it is vital that federal policymakers and Part D plan managers understand whether enrollees most in need of MTM have access to these services.

We designed the analysis reported in this article to help address that concern. Our first objective was to evaluate potential underuse of and poor adherence to evidence-based medications used in the treatment of Medicare beneficiaries with common chronic diseases over a period of several years. Findings related to this objective provide the empirical basis for assessing whether MTM eligibility criteria identify Part D enrollees at the greatest risk of underuse of and adherence to these drugs (objective 2). Our third objective was to establish the degree to which changes in eligibility criteria would affect the share of Part D enrollees offered MTM.

\section{Methods}

Although federal statistics on which Part D enrollees received MTM services are not available to researchers outside of CMS, it is possible to identify potential recipients based on the planlevel MTM eligibility requirements reported to CMS. We used such information in conjunction with Part D claims and diagnostic indicators from Part A and B claims to investigate use of and adherence to evidence-based medications to treat Medicare Part D enrollees with diabetes, congestive heart failure (CHF), and chronic obstructive pulmonary disease (COPD). Part D plans have wide latitude in selecting specific conditions for MTM eligibility but must include at least 4 among a "core" set of 7 diseases: diabetes, heart failure, hypertension, dyslipidemia, respiratory disease (including COPD), bone disease, and mental health disorders. In 2011, 97\% of Part D plans indicated they selected diabetes for MTM review, 95\% selected CHF, and $58 \%$ selected COPD. ${ }^{12}$ Because treatment regimens for all 3 conditions typically require long-term medication use, one way to evaluate the effectiveness of MTM targeting for such individuals is to determine whether plan-level MTM eligibility criteria identify those most at risk for suboptimal drug utilization behavior over an extended period of time (3 years in our case).
We are aware of no published studies that have evaluated how well MTM targeting criteria perform in this regard. Several studies have shown that increased comorbidity burden results in declining drug adherence, ${ }^{13-15}$ and we thus hypothesized that plans restricting MTM eligibility to persons with at least 3 specific chronic conditions would capture a population with higher risk of nonadherence compared with plans that required a minimum of 2 chronic conditions. We had no prior expectations regarding the relationship between suboptimal drug use and medication counts, as the literature is mixed on that score with some studies suggesting that adherence is lower among those with more drugs in their regimens ${ }^{16-18}$ and others supporting the opposite conclusion. ${ }^{19-21}$ We also assessed the relationship between suboptimal drug use and annual Part D drug spending. While all Part D plans must offer MTM services to beneficiaries who meet the annual projected drug spending criterion (as long as these individuals also meet their plan's comorbidity and drug count criteria), we wanted to test whether other drug spending cutoff points might improve the sensitivity of MTM targeting. Finally, we tracked our study cohort for 3 years (2006-2008) to determine whether the nexus between drug utilization patterns and MTM eligibility varied over time.

\section{Study Sample}

Study subjects were selected from a random 5\% sample of Medicare beneficiaries beginning on January 1, 2006, and followed through December 31, 2008, or until death (at the time the research was conducted, these were the most current data available from CMS). Inclusion criteria included a diagnosis of diabetes (International Classification of Diseases, Ninth Revision, Clinical Modification [ICD-9-CM] codes of 250.xx, 357.2, 362.02 or 366.41), CHF (ICD-9-CM codes of 389.91, 402.01, 402.11, 402.91, 404.xx or 428.xx), and/or COPD (ICD-9-CM codes of 491.xx, 492.0, 492.8, 494.0, 494.1 or 496) on at least 1 inpatient or 2 outpatients or carrier claims between July 2004 and June 2006. We required that all study subjects have continuous Part A, Part B, and Part D coverage for the entire 3-year study period or until their death month. We excluded enrollees in Medicare Advantage prescription drug (MAPD) plans because they lacked the Part A and Part B claims necessary for disease ascertainment.

\section{Measures}

We used MTM eligibility criteria for the modal Part D program in 2011 as our guide in the evaluation, since that was the most recent year for which such data were available at the time we conducted the analysis. According to CMS, the modal plan that year set MTM eligibility thresholds at $\$ 3,000$ in projected annual Part D drug spending, 3 chronic conditions, and 8 different Part D drugs. ${ }^{10}$ We used actual Part D spending to operationalize the MTM projected spending criterion. 


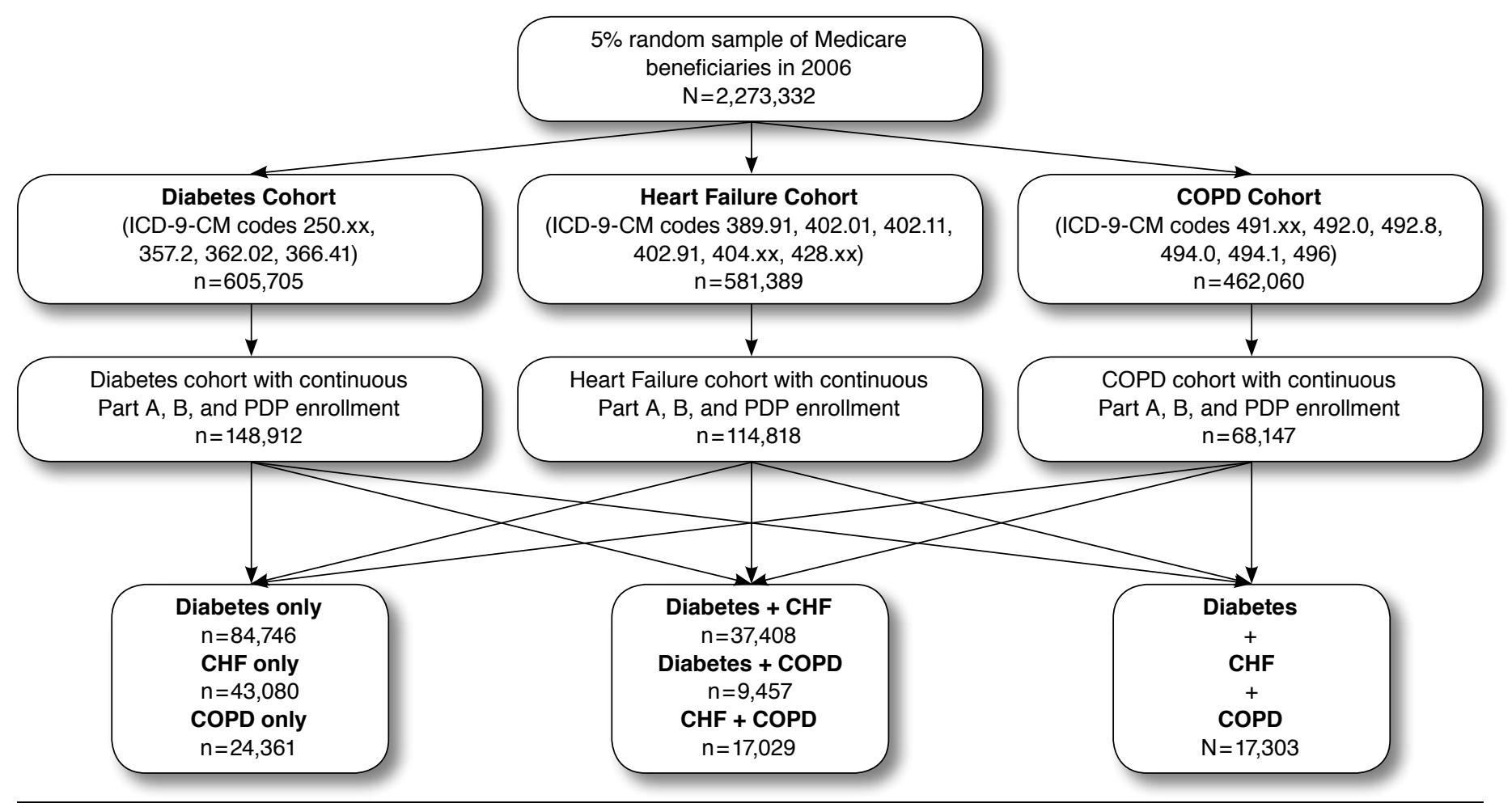

$C H F=$ congestive heart failure; $C O P D=$ chronic obstructive pulmonary disease; ICD-9-CM = International Classification of Diseases, Ninth Revision, Clinical Modification; $\mathrm{PDP}=$ prescription drug plan.

We employed 2 approaches to assess the relationship between suboptimal medication use and comorbidity burden. First, we subdivided the sample into 7 mutually exclusive cohorts: 3 cohorts restricted to beneficiaries with only 1 of the selected diseases (diabetes $=84,746, \mathrm{CHF}=43,080, \mathrm{COPD}=24,361$ ); 3 cohorts with 2 of the 3 diseases (diabetes $+\mathrm{CHF}=37,408$, diabetes $+\mathrm{COPD}=9,457, \mathrm{CHF}+\mathrm{COPD}=17,029)$; and a final cohort with all 3 conditions $(n=17,303)$. Figure 1 presents a flowchart showing how these subgroups were selected from the random 5\% Medicare sample. These divisions permitted us to observe drug utilization patterns both among Medicare beneficiaries with low levels of comorbidity (an under-studied area in drug adherence) and among beneficiaries with specific combinations of chronic diseases commonly encountered in practice. We also employed a more general comorbidity cut point that classified individuals as having $<3$ or $\geq 3$ of the CMS "core" diseases during the baseline 2006 year: diabetes, CHF, COPD, hypertension (ICD-9-CM 401.xx-404.xx), dyslipidemia (ICD9-CM 272.0-272.2), osteoarthritis (ICD-9-CM 715.xx), and depression (ICD-9-CM 311.xx).

CMS does not explicitly specify the period over which use of different drugs must occur for MTM eligibility, so we contacted
8 of the 10 largest Part D plans and determined that monthly use of 8 different chronic care drugs was the most common requirement. ${ }^{22}$ We then operationalized the Part D medication count criterion using a Red Book flag for drugs indicated for chronic care use..$^{23}$

We assessed drug utilization patterns within each disease cohort using Part D prescription drug event (PDE) files, focusing on a single evidence-based drug class for each disease: angiotensin-converting enzyme (ACE) inhibitors or angiotensin receptor blockers (ARBs) for diabetes, ${ }^{24}$ beta-blockers for heart failure, ${ }^{25}$ and controller or maintenance medications (long-acting beta agonists, inhaled corticosteroids, anticholinergics, or methylxanthines) for COPD. ${ }^{26}$ For the multiple disease cohorts, we tracked utilization of each evidence-based drug class separately; for example, ACE-inhibitors/ARBs and controller drugs for the cohort with diabetes plus COPD. We determined whether beneficiaries had any drug exposure in each study year. For beneficiaries who filled at least 1 prescription for an evidence-based drug, we calculated monthly average adherence rates using the percentage of days covered (PDC) metric recommended by CMS and the Pharmacy Quality Alliance $(\mathrm{PQA}){ }^{27} \mathrm{PDC}$ values were defined as days' supply 


\section{TABLE 1 Baseline and Longitudinal Characteristics of Study Cohorts by Disease State and Year}

\begin{tabular}{|c|c|c|c|c|c|c|c|}
\hline & \multicolumn{7}{|c|}{ Disease Cohorts } \\
\hline & $\begin{array}{c}\text { Diabetes } \\
(\mathrm{N}=84,746)\end{array}$ & $\begin{array}{c}\text { CHF } \\
(\mathrm{N}=43,080)\end{array}$ & $\begin{array}{c}\text { COPD } \\
(\mathrm{N}=24,362)\end{array}$ & $\begin{array}{c}\text { Diabetes }+ \\
\text { CHF } \\
(\mathrm{N}=37,408)\end{array}$ & $\begin{array}{c}\text { Diabetes + } \\
\text { COPD } \\
(\mathrm{N}=9,457)\end{array}$ & $\begin{array}{c}\text { CHF + COPD } \\
(\mathrm{N}=17,029)\end{array}$ & $\begin{array}{c}\text { Diabetes + } \\
\text { CHF + COPD } \\
(\mathrm{N}=17,303)\end{array}$ \\
\hline \multicolumn{8}{|c|}{ Panel 1: Baseline beneficiary characteristics } \\
\hline Low-income subsidy (\%) & 64.1 & 64.8 & 65.7 & 74.2 & 75.4 & 70.3 & 80.2 \\
\hline \multicolumn{8}{|l|}{ Age (\%) } \\
\hline$<65-$ SSDI & 22.0 & 10.5 & 21.9 & 13.9 & 24.1 & 10.4 & 15.2 \\
\hline $65-74$ & 31.0 & 14.1 & 28.9 & 22.6 & 31.4 & 19.3 & 26.4 \\
\hline $75-84$ & 32.4 & 30.0 & 33.0 & 35.5 & 32.1 & 35.1 & 36.9 \\
\hline $85+$ & 14.6 & 45.4 & 16.2 & 28.0 & 12.4 & 35.2 & 21.4 \\
\hline \multicolumn{8}{|l|}{ Sex $(\%)$} \\
\hline Female & 65.7 & 72.5 & 61.9 & 70.0 & 61.3 & 66.1 & 65.5 \\
\hline Male & 34.3 & 27.5 & 38.1 & 30.0 & 38.7 & 33.9 & 34.5 \\
\hline \multicolumn{8}{|l|}{ Race/ethnicity (\%) } \\
\hline White & 72.7 & 81.2 & 86.9 & 70.7 & 79.5 & 86.1 & 77.2 \\
\hline Black & 16.4 & 12.7 & 7.2 & 19.5 & 11.9 & 8.8 & 15.1 \\
\hline Hispanic & 4.7 & 2.4 & 2.4 & 4.8 & 4.5 & 2.5 & 4.3 \\
\hline Other & 6.2 & 3.7 & 3.5 & 5.0 & 4.1 & 2.6 & 3.3 \\
\hline \multicolumn{8}{|l|}{ Region (\%) } \\
\hline Northeast & 19.3 & 19.5 & 17.7 & 19.7 & 18.8 & 18.3 & 18.5 \\
\hline North central & 23.5 & 26.0 & 24.2 & 23.8 & 23.1 & 25.3 & 24.7 \\
\hline South & 40.4 & 39.0 & 43.4 & 40.8 & 43.8 & 42.0 & 43.5 \\
\hline West & 16.9 & 15.5 & 14.8 & 15.6 & 14.3 & 14.4 & 13.3 \\
\hline \multicolumn{8}{|c|}{ Panel 2: Longitudinal characteristics of disease cohorts } \\
\hline \% who died by December 31, 2008 & 12.9 & 37.2 & 23.2 & 37.3 & 23.4 & 49.7 & 50.6 \\
\hline \multicolumn{8}{|l|}{ Mean annual drug spending (SD) } \\
\hline 2006 & $\begin{array}{l}\$ 3,807 \\
(4,002)\end{array}$ & $\begin{array}{l}\$ 3,307 \\
(3,775)\end{array}$ & $\begin{array}{c}\$ 3,852 \\
(4,365)\end{array}$ & $\begin{array}{l}\$ 4,571 \\
(4,398)\end{array}$ & $\begin{array}{l}\$ 5,251 \\
(5,136)\end{array}$ & $\begin{array}{l}\$ 4,120 \\
(4,269)\end{array}$ & $\begin{array}{c}\$ 5,366 \\
(4,584)\end{array}$ \\
\hline 2008 & $\begin{array}{c}\$ 4,359 \\
(4,945) \\
\end{array}$ & $\begin{array}{l}\$ 3,628 \\
(4,607) \\
\end{array}$ & $\begin{array}{r}\$ 4,580 \\
(5,441) \\
\end{array}$ & $\begin{array}{l}\$ 5,166 \\
(5,449) \\
\end{array}$ & $\begin{array}{r}\$ 6,250 \\
(6,554) \\
\end{array}$ & $\begin{array}{l}\$ 4,737 \\
(6,653) \\
\end{array}$ & $\begin{array}{r}\$ 6,290 \\
(6,211) \\
\end{array}$ \\
\hline \multicolumn{8}{|l|}{ Mean core comorbidities (SD) } \\
\hline 2006 & $2.9(0.9)$ & $2.8(1.0)$ & $2.7(1.0)$ & $4.1 \quad(0.9)$ & $4.2(0.9)$ & $4.0(1.0)$ & $5.2(0.9)$ \\
\hline 2008 & $3.6(1.1)$ & $3.5(1.2)$ & $3.5(1.2)$ & $4.6(1.1)$ & $4.9(1.1)$ & $4.5(1.1)$ & $5.6(1.0)$ \\
\hline \multicolumn{8}{|c|}{ Mean monthly chronic medications (SD) } \\
\hline 2006 & $3.8(2.5)$ & $3.8(2.4)$ & $3.2(2.3)$ & $5.0(2.9)$ & $4.6(2.9)$ & $4.3(2.6)$ & $5.6(3.1)$ \\
\hline 2008 & $4.1(2.7)$ & $4.0(2.5)$ & $3.6(2.5)$ & $5.4(3.0)$ & $5.1(3.1)$ & $4.8(2.9)$ & $6.2(3.4)$ \\
\hline \multicolumn{8}{|c|}{ Panel 3: Modal 2011 MTM eligibility criteria ${ }^{a}$} \\
\hline \multicolumn{8}{|c|}{ Met criteria (\%) } \\
\hline 2006 & 18.5 & 15.3 & 13.4 & 40.3 & 38.8 & 31.6 & 53.5 \\
\hline 2008 & 23.3 & 14.8 & 17.1 & 31.3 & 36.2 & 22.0 & 33.8 \\
\hline \multicolumn{8}{|l|}{ Failed drug spending criterion (\%) } \\
\hline 2006 & 54.9 & 61.5 & 55.3 & 42.4 & 38.3 & 49.8 & 34.3 \\
\hline 2008 & 55.0 & 70.7 & 58.0 & 56.4 & 44.8 & 66.3 & 58.2 \\
\hline \multicolumn{8}{|l|}{ Failed core condition criterion (\%) } \\
\hline 2006 & 26.9 & 35.7 & 39.8 & 4.0 & 3.6 & 5.8 & 0.0 \\
\hline 2008 & 10.4 & 19.9 & 19.7 & 2.2 & 1.2 & 3.4 & 0.0 \\
\hline \multicolumn{8}{|l|}{ Failed drug count criterion (\%) } \\
\hline 2006 & 74.1 & 74.3 & 80.8 & 49.6 & 56.5 & 59.3 & 35.7 \\
\hline 2008 & 71.3 & 79.1 & 79.5 & 61.5 & 59.5 & 72.5 & 60.1 \\
\hline \multicolumn{8}{|c|}{$\begin{array}{l}\text { Note: Cohorts are mutually exclusive, and columns add to more than } 100 \% \text { because persons may fail multiple criteria. } \\
\text { a2011 MTM modal criteria = annual drug spending } \geq \$ 3,000 \text {, at least } 3 \text { core conditions, and at least } 1 \text { month with } 8 \text { or more chronic medications. } \\
\text { CHF = congestive heart failure; } C O P D=\text { chronic obstructive pulmonary disease; } M T M=\text { medication therapy management; SD=standard deviation; SSDI=Social Security } \\
\text { Disability Income. }\end{array}$} \\
\hline
\end{tabular}


on hand per month divided by days in the month (excluding inpatient days and days following death) and then multiplying the result by 100. For 2007 and 2008, we calculated carryover of unused drugs from the prior year. Because this was impossible for 2006, we restricted the analysis that year to drug fills observed from April through December. We computed the proportion of each study cohort with PDC values $<0.8$ and $\geq 0.8$ as a means of ascertaining those with good adherence. A cutoff of PDC $\geq 0.8$ is commonly used for designating adequate adherence, and this threshold is also recommended by CMS and PQA. ${ }^{28}$

\section{Analytic Strategy}

We prepared descriptive cross-tabulations showing changes in drug use over time, highlighting the proportions reaching and failing to reach eligibility thresholds for the modal 2011 MTM plan. We tested for statistically significant differences between the 2 sets of proportions using t-tests with the $P$ value set at $<0.05$. Next, we demonstrated how exposure and adherence to evidence-based medications varied by disease cohort, MTM eligibility criteria, and year. Finally, we examined characteristics of 2008 survivors to see how potential policy changes in MTM thresholds would affect the percentage eligible for MTM intervention that year.

This study was approved by the University of Maryland Baltimore's Institutional Review Board.

\section{Results}

As shown in Panel 1 of Table 1 , beneficiaries with the 3 conditions exhibited markedly different profiles. Panel 2 of the same table shows longitudinal changes within each cohort over the study period. Cumulative death rates varied between 13\% (diabetes alone) and 51\% (diabetes + CHF + COPD). Survivors in each cohort had between 0.4 and 0.8 new core comorbidities over the 3-year span. Mean annual Part D spending grew by between $10 \%$ and $19 \%$, while mean monthly counts of Part D medications grew by between $5 \%$ and $12 \%$.

Panel 3 of Table 1 shows proportions of each cohort meeting and not meeting the modal 2011 MTM criteria set. Had the 2011 criteria been applied in 2006-2008, relatively few beneficiaries in our samples would have been eligible for MTM services. Eligibility rates were higher among those with greater disease burden. In each year, the main reason for exclusion was use of fewer than 8 medications per month, followed by drug spending and comorbidity counts. Except for the 3 cohorts restricted to just a single condition, the MTM chronic condition criterion excluded few beneficiaries, and even in these cohorts, a greater share of beneficiaries failed the drug count or drug spending criteria than the chronic condition criterion.

Table 2 shows the proportion of beneficiaries taking drugs in each medication class. Overall exposure was low, particularly for COPD controller medications. About 50\% of benefi- ciaries with COPD took recommended medications in 2006 and 2008. For heart failure patients, exposure to beta-blockers varied between $46 \%$ and $63 \%$ depending on comorbidities. Fewer than $68 \%$ of beneficiaries with diabetes took an ACEinhibitor or ARB even if they had concomitant heart failure. Except for COPD patients, exposure rates rose slightly over time. Exposure was consistently higher among those with drug spending $\geq \$ 3,000$, core comorbidities $\geq 3$, and monthly medications $\geq 8$.

Adherence among users of evidence-based medications was also low (Table 3). The worst performance was among COPD patients, with fewer than $35 \%$ having PDC values of 0.8 or better. Proportions of beneficiaries with good adherence to other drug classes ranged between $48 \%$ and $61 \%$. Higher drug spenders had better adherence rates than lower spenders with a similar pattern evident among beneficiaries taking $\geq 8$ chronic medications compared with those taking fewer medications. These concurrent patterns explain why adherence rates were consistently higher among those meeting the modal 2011 MTM criteria compared with those who did not $(P<0.001$ for all contrasts).

Table 4 shows how changing MTM criteria thresholds would affect the percentage of 2008 survivors eligible for MTM intervention. The first point of interest is that for our sample MTM eligibility is insensitive to the selection of 2 (Panel 1) or 3 (Panel 2) chronic conditions. Corresponding cells in each panel differ within a very narrow range of $0.6 \%$ and $5.5 \%$. The second point is that dropping the annual drug spending threshold from the 2011 level of $\$ 3,000$ would have virtually no impact as long as Part D plans are able to restrict MTM eligibility to beneficiaries with a minimum of 8 Part $\mathrm{D}$ drugs a month. As shown in the bottom rows of each panel, even eliminating the annual drug spending criterion would increase MTM eligibility by less than 6 percentage points among plans using the 8-drug threshold. The policy with the greatest impact on MTM eligibility is drug counts. A requirement that plans use the current-law minimum of 2 different drugs would increase MTM eligibility from about $31 \%$ to nearly $52 \%$ in our sample.

\section{Discussion}

We found that use of evidence-based medications among Medicare Part D enrollees with diabetes, CHF, and COPD was suboptimal by virtually any standard of care. Although one would not expect every beneficiary in each disease cohort to be a candidate for the medication classes selected for evaluation, most patients with these diseases are likely to benefit based on current guidelines. ${ }^{24-26}$ Our data provide numerous indications of systematic underuse of these drugs. A few examples make this clear:

- In none of the disease cohorts we tracked were more than $68 \%$ exposed to an evidence-based drug in any given year (data not shown for 2007). 
Should Eligibility for Medication Therapy Management Be Based on Drug Adherence?

\section{TABLE 2 Percentage of Disease Cohorts with Evidence-Based} Medication Use by MTM Eligibility Criteria and Year

\begin{tabular}{|c|c|c|c|c|c|c|c|c|c|c|c|c|}
\hline \multirow[b]{2}{*}{$\begin{array}{l}\text { Beneficiary } \\
\text { Characteristics } \\
\text { by Year }\end{array}$} & \multirow{2}{*}{$\begin{array}{c}\text { Diabetes } \\
\text { ACEI/ } \\
\text { ARBs } \\
(84,746)\end{array}$} & \multirow{2}{*}{$\begin{array}{c}\text { CHF } \\
\begin{array}{c}\text { Beta- } \\
\text { blockers } \\
(43,080)\end{array}\end{array}$} & \multirow{2}{*}{\begin{tabular}{|c|} 
COPD \\
Controller \\
Drugs \\
$(24,362)$ \\
\end{tabular}} & \multicolumn{2}{|c|}{ Diabetes+CHF } & \multicolumn{2}{|c|}{ Diabetes + COPD } & \multicolumn{2}{|c|}{$\mathrm{CHF}+\mathrm{COPD}$} & \multicolumn{3}{|c|}{ Diabetes $+\mathrm{CHF}+\mathrm{COPD}$} \\
\hline & & & & $\begin{array}{c}\text { ACEI/ } \\
\text { ARBs } \\
(37,408)\end{array}$ & $\begin{array}{c}\text { Beta- } \\
\text { blockers } \\
(37,408)\end{array}$ & $\begin{array}{c}\text { ACEI/ } \\
\text { ARBs } \\
(9,457)\end{array}$ & $\begin{array}{c}\text { Controller } \\
\text { Drugs } \\
(9,457)\end{array}$ & $\begin{array}{c}\text { Beta- } \\
\text { blockers } \\
(17,029)\end{array}$ & $\begin{array}{c}\text { Controller } \\
\text { Drugs } \\
(17,029)\end{array}$ & $\begin{array}{c}\text { ACEI/ } \\
\text { ARBs } \\
(17,303)\end{array}$ & $\begin{array}{c}\text { Beta- } \\
\text { blockers } \\
(17,303)\end{array}$ & $\begin{array}{c}\text { Controller } \\
\text { Drugs } \\
(17,303)\end{array}$ \\
\hline
\end{tabular}

All beneficiaries (\%)

\begin{tabular}{|c|c|c|c|c|c|c|c|c|c|c|c|c|}
\hline 2006 & 61.5 & 51.5 & 52.7 & 65.4 & 58.1 & 55.0 & 49.4 & 45.8 & 50.4 & 62.0 & 53.8 & 50.2 \\
\hline 2008 & 66.4 & 56.1 & 51.8 & 67.2 & 62.6 & 58.9 & 47.8 & 49.0 & 51.2 & 61.7 & 56.1 & 49.2 \\
\hline
\end{tabular}

Annual drug spending $<\$ 3,000(\%)$

\begin{tabular}{|c|c|c|c|c|c|c|c|c|c|c|c|c|}
\hline 2006 & 56.8 & 47.8 & 42.6 & 56.7 & 49.6 & 47.4 & 35.7 & 42.1 & 37.6 & 51.5 & 45.9 & 33.4 \\
\hline 2008 & 62.0 & 54.2 & 38.0 & 60.6 & 56.5 & 51.1 & 30.5 & 45.8 & 35.4 & 51.1 & 49.2 & 31.3 \\
\hline
\end{tabular}

Annual drug spending $\geq \$ 3,000(\%)$

\begin{tabular}{|c|c|c|c|c|c|c|c|c|c|c|c|c|}
\hline 2006 & 67.4 & 57.3 & 65.2 & 71.8 & 64.4 & 59.7 & 57.9 & 49.5 & 63.1 & 67.4 & 57.9 & 58.9 \\
\hline 2008 & 71.0 & 58.9 & 65.8 & 71.5 & 66.7 & 63.1 & 56.9 & 51.7 & 64.3 & 66.5 & 59.3 & 57.4 \\
\hline
\end{tabular}

Core chronic conditions $<3(\%)$

\begin{tabular}{|c|c|c|c|c|c|c|c|c|c|c|c|c|}
\hline 2006 & 43.0 & 40.9 & 54.7 & 33.8 & 29.9 & 16.9 & 53.8 & 20.0 & 50.8 & - & - & - \\
\hline 2008 & 37.3 & 38.5 & 52.5 & 27.9 & 19.9 & 8.1 & 51.4 & 20.5 & 53.8 & - & - & - \\
\hline \multicolumn{13}{|c|}{ Core chronic conditions $\geq 3(\%)$} \\
\hline 2006 & 68.4 & 57.3 & 51.4 & 66.7 & 59.3 & 56.4 & 49.2 & 47.4 & 50.4 & 62.0 & 53.8 & 50.2 \\
\hline 2008 & 69.0 & 58.3 & 51.7 & 67.4 & 62.8 & 59.2 & 47.8 & 49.3 & 51.1 & 61.7 & 56.1 & 49.2 \\
\hline \multicolumn{13}{|c|}{ Monthly medications <8 (\%) } \\
\hline 2006 & 56.9 & 46.1 & 48.1 & 55.0 & 46.2 & 46.6 & 39.3 & 38.2 & 40.8 & 46.7 & 38.7 & 33.8 \\
\hline 2008 & 61.2 & 50.2 & 45.4 & 57.8 & 51.7 & 49.3 & 35.5 & 40.2 & 39.9 & 47.6 & 40.9 & 31.5 \\
\hline \multicolumn{13}{|c|}{ Monthly medications $\geq 8$ (\%) } \\
\hline 2006 & 74.8 & 67.0 & 72.1 & 75.6 & 69.9 & 66.0 & 62.6 & 56.9 & 64.5 & 70.4 & 62.1 & 59.2 \\
\hline 2008 & 77.8 & 70.7 & 71.7 & 75.5 & 72.3 & 69.3 & 61.1 & 60.1 & 65.3 & 69.1 & 64.1 & 58.5 \\
\hline \multicolumn{13}{|c|}{ Did not meet 2011 modal MTM eligibility criteriaa (\%) } \\
\hline 2006 & 58.1 & 48.6 & 49.8 & 57.9 & 50.3 & 47.9 & 40.6 & 41.1 & 42.3 & 52.1 & 44.9 & 36.7 \\
\hline 2008 & 62.6 & 52.9 & 46.3 & 60.8 & 55.9 & 51.6 & 36.4 & 43.9 & 41.3 & 51.8 & 47.0 & 34.6 \\
\hline \multicolumn{13}{|c|}{ Met 2011 modal MTM eligibility criteriaa (\%) } \\
\hline 2006 & 76.9 & 67.5 & 71.7 & 76.5 & 69.8 & 66.2 & 63.4 & 56.0 & 67.9 & 70.6 & 61.5 & 61.8 \\
\hline 2008 & 77.6 & 68.4 & 73.7 & 75.6 & 71.4 & 68.7 & 62.9 & 58.4 & 69.1 & 69.6 & 63.4 & 60.9 \\
\hline
\end{tabular}

Note: Cohorts are mutually exclusive.

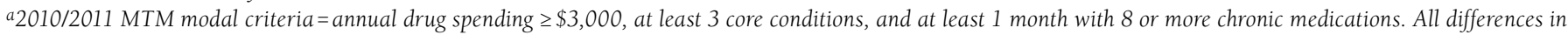
percentages of those meeting and not meeting the modal criteria in each year are statistically significant at $P<0.001$.

$A C E I=$ angiotensin-converting enzyme inhibitor; $A R B=$ angiotensin receptor blockers; $C H F=$ congestive heart failure; COPD =chronic obstructive pulmonary disease;

MTM=medication therapy management.

- Controller medications are the mainstay for reducing hospitalizations for acute exacerbations of COPD, ${ }^{26}$ yet only half of beneficiaries with COPD received a single controller medication in any year.

- ACE-inhibitors and ARBs are recommended in treatment guidelines for both diabetes and $\mathrm{CHF}^{24,25}$ yet a third with both diseases failed to receive these drugs in any year.

The evidence regarding drug adherence among users of evidence-based medications was even more troubling:

- In none of the disease cohorts did more than $62 \%$ of beneficiaries maintain adherence rates above PDC $\geq 0.8$ in any year. Between $41 \%$ and $85 \%$ of non-MTM eligible individuals had PDC values below 0.8 in all 3 years observed.

- Adherence rates were particularly poor for COPD control- ler medications. Fewer than $35 \%$ of users of these drugs maintained $\mathrm{PDC} \geq 0.8$ in any year, with rates between $25 \%$ and $30 \%$ for those with concomitant diabetes and heart failure.

Our findings indicate that had the modal 2011 MTM eligibility criteria been applied in the 2006-2008 period, few beneficiaries would have been targeted for intervention (the actual MTM criteria in place during these years were much more stringent than the 2011 criteria). ${ }^{29}$ More striking is the fact that those who would have been selected had systematically better use and adherence with evidence-based medications compared with those who failed on 1 or more of the individual criteria used to establish MTM eligibility. It is possible that actual MTM interventions were partially responsible for this observed pattern, but a more plausible explanation lies in the 
Should Eligibility for Medication Therapy Management Be Based on Drug Adherence?

\section{TABLE 3 Percentage of Evidence-Based Drug Users with PDC $\geq 0.8$} by Drug Class and MTM Eligibility Criteria and Year

\begin{tabular}{|c|c|c|c|c|c|c|c|c|c|c|c|c|}
\hline \multirow[b]{2}{*}{$\begin{array}{l}\text { Drug User } \\
\text { Characteristics } \\
\text { by Year }\end{array}$} & \multirow{2}{*}{\begin{tabular}{|c} 
Diabetes \\
ACEI/ \\
ARBs \\
$(52,155)$
\end{tabular}} & \multirow{2}{*}{\begin{tabular}{|c|} 
CHF \\
Beta- \\
blockers \\
$(22,174)$
\end{tabular}} & \multirow{2}{*}{\begin{tabular}{|c|} 
COPD \\
Controller \\
Drugs \\
$(12,841)$
\end{tabular}} & \multicolumn{2}{|c|}{ Dlabetes + CHF } & \multicolumn{2}{|c|}{ Diabetes + COPD } & \multicolumn{2}{|c|}{$\mathrm{CHF}+\mathrm{COPD}$} & \multicolumn{3}{|c|}{ Diabetes + CHF + CUPL } \\
\hline & & & & $\begin{array}{r}\mathrm{AC} \\
\mathrm{AI} \\
(24\end{array}$ & $(2$ & $\begin{array}{r}\text { A } \\
(5\end{array}$ & $\begin{array}{l}\text { Dr } \\
(4,\end{array}$ & $\begin{array}{r}\text { B } \\
\text { blo } \\
(7\end{array}$ & $\begin{array}{c}\mathrm{D} \\
(8\end{array}$ & $\begin{array}{r}\text { A } \\
(19\end{array}$ & & 57) \\
\hline
\end{tabular}

All beneficiaries (\%)

\begin{tabular}{|c|c|c|c|c|c|c|c|c|c|c|c|c|}
\hline 2006 & 57.5 & 56.7 & 28.6 & 52.3 & 55.1 & 52.2 & 25.9 & 50.1 & 26.9 & 47.5 & 49.8 & 24.6 \\
\hline 2008 & 61.0 & 61.4 & 34.6 & 58.2 & 58.9 & 58.0 & 31.9 & 57.1 & 33.9 & 55.3 & 57.7 & 29.9 \\
\hline
\end{tabular}

Annual drug spending $<\$ 3,000(\%)$

\begin{tabular}{l|l|l|l|l|l|l|l|l|l|l|l|l}
\hline 2006 & 50.2 & 50.3 & 15.4 & 40.8 & 42.3 & 39.8 & 10.7 & 40.0 & 14.0 & 33.6 & 35.2 & 11.8 \\
\hline 2008 & 54.5 & 58.0 & 17.4 & 50.5 & 51.6 & 46.1 & 13.2 & 52.0 & 19.2 & 45.1 & 48.4 & 19.7 \\
\hline
\end{tabular}

Annual drug spending $\geq \$ 3,000(\%)$

\begin{tabular}{l|l|l|l|l|l|l|l|l|l|l|l|l}
\hline 2006 & 65.0 & 65.3 & 39.2 & 59.0 & 62.3 & 58.4 & 31.7 & 58.7 & 34.5 & 53.1 & 55.8 & 28.4 \\
\hline 2008 & 66.9 & 66.0 & 44.5 & 62.5 & 63.0 & 63.1 & 36.2 & 60.9 & 39.7 & 58.9 & 61.2 & 32.5 \\
\hline
\end{tabular}

Core chronic conditions $<3(\%)$

\begin{tabular}{l}
\hline 2006 \\
\hline 2008
\end{tabular}

Note: Cohorts are mutually exclusive.

a2010/2011 MTM modal criteria $=$ annual drug spending $\geq \$ 3,000$, at least 3 core conditions, and at least 1 month with 8 or more chronic medications. All differences in percentages of those meeting and not meeting the modal criteria in each year are statistically significant at $P<0.001$.

$A C E I=$ angiotensin-converting enzyme inhibitor; $A R B=$ angiotensin receptor blockers; $C H F=$ congestive heart failure; $C O P D=$ chronic obstructive pulmonary disease;

$M T M=$ medication therapy management; $P D C=$ proportion of days covered.

underlying relationship between MTM targeting criteriaand drug utilization patterns. We found that higher levels of drug spending, comorbidity counts, and medication fills were all positively associated with exposure to evidence-based medications. Thus, limiting MTM eligibility to beneficiaries meeting relatively high threshold levels on each criterion is guaranteed to select a group of beneficiaries with drug exposure rates higher than the population average.

We discovered that the most restrictive of the 2011 modal criteria is the requirement that beneficiaries take 8 or more different chronic Part D drugs. Because Part D plans are not required to set the threshold that high, one must assume they do so in order to limit the number of enrollees offered MTM services. Were plans to lower the drug count threshold to the federal minimum of 2 , we estimate that MTM eligibility would increase by almost two thirds.

\section{Limitations}

Our findings should be reviewed in the light of several limitations. First, we did not have information regarding which beneficiaries in our study cohorts actually received MTM services between 2006 and 2008. Although we are reasonably certain that few beneficiaries we classified as "failing to meet the modal 2011 MTM criteria" received MTM interventions given that the drug spending criterion set by CMS was $\$ 4,000$ prior to 2010, we can assume that some fraction of those above these eligibility thresholds did receive MTM services.

Second, we had no way of knowing either the form or the effectiveness of MTM interventions in improving medication utilization patterns among those receiving interventions during the study period. As previously noted, some of the difference in the utilization patterns we observed between the 2 


\section{TABLE 4 Estimated Effects of Changing MTM Minimum Threshold Criteria for Core Chronic Condition Counts, Annual Drug Spending, and Part D Drug Counts on MTM Eligibility for the Study Population in $2008^{a}$}

Panel 1: Percentage Eligible for MTM Based on Minimum of 2 Core Chronic Conditions

\begin{tabular}{|c|c|c|c|c|c|c|c|}
\hline \multirow{2}{*}{$\begin{array}{l}\text { MTM Drug Criteria } \\
\text { Thresholds }\end{array}$} & \multicolumn{7}{|c|}{ Minimum Required Annual Drug Spending } \\
\hline & None & $\$ 500$ & $\$ 1,000$ & $\$ 1,500$ & $\$ 2,000$ & $\$ 2,500$ & $\$ 3,000$ \\
\hline \multicolumn{8}{|c|}{ Minimum required monthly Part D chronic drug counts } \\
\hline 1 & 97.4 & 92.6 & 85.9 & 78.4 & 70.6 & 62.4 & 53.8 \\
\hline 2 & 95.6 & 91.9 & 85.6 & 78.2 & 70.5 & 62.3 & 53.8 \\
\hline 3 & 91.3 & 89.0 & 83.6 & 76.9 & 69.7 & 61.8 & 53.4 \\
\hline 4 & 83.7 & 82.5 & 78.7 & 73.3 & 67.1 & 60.0 & 52.3 \\
\hline 5 & 73.1 & 72.6 & 70.3 & 66.5 & 61.8 & 56.2 & 49.7 \\
\hline 6 & 60.7 & 60.5 & 59.3 & 57.0 & 53.8 & 49.8 & 44.9 \\
\hline 7 & 48.1 & 48.0 & 47.5 & 46.2 & 44.4 & 41.9 & 38.6 \\
\hline 8 & 36.7 & 36.7 & 36.5 & 35.9 & 34.9 & 33.5 & 31.5 \\
\hline
\end{tabular}

Panel 2: Percentage Eligible for MTM Based on Minimum of 3 Core Chronic Conditions

\section{MTM Drug Criteria}

Thresholds
Minimum Required Annual Drug Spending

\begin{tabular}{l|l|l}
$\$ 1,000$ & $\$ 1,500$ & $\$ 2,000$
\end{tabular}

$\$ 2,500$

$\$ 3,000$

\begin{tabular}{l|c|c|c|c|c|c|c}
\hline Minimum required monthly Part D chronic drug counts & \multicolumn{5}{l|}{} \\
\hline 1 & 91.9 & 87.8 & 81.9 & 74.9 & 67.7 & 59.9 & 51.7 \\
\hline 2 & 90.5 & 87.3 & 81.7 & 74.8 & 67.6 & 59.8 & 51.7 \\
\hline 3 & 86.8 & 84.8 & 79.9 & 73.7 & 66.9 & 59.4 & 51.4 \\
\hline 4 & 80.2 & 79.1 & 75.6 & 70.5 & 64.6 & 57.9 & 50.5 \\
\hline 5 & 70.5 & 70.1 & 67.9 & 64.3 & 59.7 & 54.4 & 48.1 \\
\hline 6 & 58.9 & 58.8 & 57.6 & 55.4 & 52.4 & 48.5 & 43.7 \\
\hline 7 & 47.0 & 46.9 & 46.4 & 45.2 & 43.4 & 41.0 & 37.7 \\
\hline 8 & 36.0 & 36.0 & 35.8 & 35.2 & 34.2 & 32.8 & 30.9 \\
\hline
\end{tabular}

${ }^{a}$ Cells represent the estimated percentage of the total study population in $2008(\mathrm{~N}=167,429)$ that would be eligible for MTM review based on the combination of criteria indicated.

MTM=medication therapy management

groups may be due to effective interventions, but our analysis suggests that Medicare beneficiaries who take more chronic care medications overall are more adherent to evidence-based guidelines for specific diseases irrespective of MTM review. This interpretation is consistent with research showing a positive association between drug adherence and total prescription fills for persons with various chronic diseases. ${ }^{19-21}$

A third potential limitation is that we modeled MTM eligibility under the modal 2011 Part D plan using a minimum of 8 different drugs in any given month. Our review of plan eligibility criteria suggested that another common threshold was 8 different drugs per quarter. To see if using this threshold would change our study results, we re-analyzed our data using the less stringent criterion and discovered that it made no substantive difference.

Fourth, we restricted the analyses to exposure and adherence to evidence-based medications and did not address other drug-related problems that MTM reviews are designed to address. We consider evidence of use and adherence with guideline-recommended therapies to be the keystone of any comprehensive medication review process. Adverse outcomes from underuse of essential medications are a significant contributor to avoidable hospitalizations and have been shown to be more important than medication errors in driving emergency services..$^{30}$ Also, many drug problems including drugdrug interactions, incorrect drug dose or duration of therapy, therapeutic duplication, age/gender-related contraindications, and prescribing of harmful or inappropriate medications are best captured at point of sale rather than waiting for MTM review. Federal regulations require that Part D plans have concurrent drug utilization review screening programs designed to catch such problems at the point a prescription is dispensed. In addition, every Part D plan must have an internal Medication Error Identification and Reduction (MEIR) process designed to collect information on medication errors and resolve them. Given these other safeguards, the primary role of MTM should be to evaluate the patient's entire medication regimen, focusing on indications where there is no drug, adherence with indicated drugs, drugs for which there is no indication, and possible failures of the drug screening programs to catch problematic interactions or errors. 
A final limitation is that we reviewed medication regimens for enrollees in stand-alone prescription drug plans and were unable to assess adherence patterns for MAPD enrollees. It has been argued that managed care plans have a greater incentive to effectively manage medications because they stand to gain from cost offsets associated with optimal drug use. ${ }^{31}$ However, that proposition has yet to be confirmed.

\section{Conclusions}

Our findings suggest that current MTM eligibility criteria are not optimally targeted to capture underuse of and poor adherence to evidence-based medications for prevalent chronic diseases in the elderly. This is not to suggest that the criteria be reversed to focus only on beneficiaries with suboptimal medication utilization behaviors. MTM reviews address other medication-related problems that may also be associated with drug spending, comorbidity, and medication counts, although that presumption should be formally assessed.

We do worry that current MTM eligibility criteria systematically exclude review of beneficiaries falling below any 1 of the 3 criteria thresholds. This is a policy concern because, based on our analysis, low spenders taking fewer medications tend to be least likely to receive evidence-based medication, and those who do tend to be least adherent. Patients who do not qualify for MTM could benefit from improved adherence, including those with fewer chronic conditions and lower spending and drug counts. At a minimum, policymakers and plan sponsors should weigh the pros and cons of loosening restrictive MTM eligibility criteria to target patients with potentially greater needs. The most recent CMS draft Call Letter, which provides guidance to Part D sponsors as they design plan offerings for the upcoming year, encourages plans to look beyond the minimum eligibility criteria and offer MTM to a broader population of beneficiaries who could benefit from these services, including beneficiaries who have filled at least 1 prescription for an antihypertensive medicine. ${ }^{32}$ Given that we found suboptimal use among low utilizers for all 3 conditions in our study, we recommend that CMS consider further encouraging participating plans to lower their Part D drug count thresholds for patients with any qualifying chronic condition.

The significant declines we observed in use of evidencebased medicines over time represent another source of concern as beneficiaries who initially qualify for MTM services in one year may become ineligible in the future if their medication counts or drug spending fall below the eligibility thresholds. Allowing for continuous MTM qualification is one way to target beneficiaries most at risk for therapy discontinuation.

Ultimately, the question of how MTM services are best targeted depends on who can benefit most from intervention. The evidence base on this issue is extremely thin. Early reviews of Medicare MTM effectiveness detail widely divergent approaches, but empirical evidence of success remains lim- ited. ${ }^{6-9}$ The Part D drug benefit has increased utilization of prescribed medications for millions of Medicare beneficiaries, particularly for those without drug coverage prior to 2006. ${ }^{33-35}$ Future research needs to focus on the degree to which this support has fostered appropriate use of evidence-based medications. In particular, empirical research is needed to determine whether MTM programs reduce gaps between evidence-based standards and patterns of medication use in the Medicare population. These studies should address the relative efficacy of different approaches to MTM and how best to target such services.

\section{Authors}

BRUCE STUART, PhD, is Director, The Peter Lamy Center on Drug Therapy and Aging, and Professor, Department of Pharmaceutical Health Services Research, and F. ELLEN LOH, MBA, BSPharm, is Graduate Research Assistant, Department of Pharmaceutical Health Services Research, University of Maryland School of Pharmacy, Baltimore, Maryland. LAURA MILLER, PhD, is Senior Economist, National Association of Chain Drug Stores, Arlington, Virginia, and PAMELA ROBERTO, MPP, is Senior Director, Policy and Research, Pharmaceutical Research and Manufacturers of America, Washington, DC.

AUTHOR CORRESPONDENCE: Bruce Stuart, PhD, Department of Pharmaceutical Health Services Research, University of Maryland School of Pharmacy, 220 Arch St., Rm. 12-212, Baltimore, MD 21201. Tel.: 410.706.5389; Fax: 410.706.1488;

E-mail:bstuart@rx.umaryland.edu.

\section{DISCLOSURES}

This research was supported by a grant from the National Association of Chain Drug Stores (NACDS) with additional support from the Pharmaceutical Research and Manufacturers of America (PhRMA). Miller is an employee of NACDS. Roberto is an employee of PhRMA. Stuart has received additional grant support from PhRMA.

Concept and design were developed by Stuart, Miller, and Roberto. Data were collected by Stuart and Loh and interpreted by all authors. The manuscript was written by Stuart with the assistance of the other authors.

\section{REFERENCES}

1. Hirsch JD, Gonzales M, Rosenquist A, Miller TA, Gilmer TP, Best BM. Antiretroviral therapy adherence, medication use, and health care costs during 3 years of a community pharmacy medication therapy management program for Medi-Cal beneficiaries with HIV/AIDS. J Manag Care Pharm. 2011;17(3):213-23. Available at: http://amcp.org/WorkArea/DownloadAsset. aspx?id $=8973$.

2. Ramalho de Oliveira D, Brummel AR, Miller DB. Medication therapy management: 10 years of experience in a large integrated health care system. J Manag Care Pharm. 2010;16(3):185-95. Available at: http://amcp.org/ WorkArea/DownloadAsset.aspx?id=8313. 
3. Barnett MJ, Frank J, Wehring H, et al. Analysis of pharmacist-provided medication therapy management (MTM) services in community pharmacies over 7 years. J Manag Care Pharm. 2009;15(1):18-31. Available at: http:// amcp.org/WorkArea/DownloadAsset.aspx?id=8064.

4. Moore JM, Shartle D, Faudskar L, Matlin OS, Brennan TA. Impact of a patient-centerd pharmacy program and intervention in a high-risk group. J Manag Care Pharm. 2013;19(3):228-36. Available at: http://amcp.org/ WorkArea/DownloadAsset.aspx?id=16313.

5. Shoemaker SJ, Pozniak A, Subramanian R, Maunch D. Effect of 6 managed care pharmacy tools: a review of the literature. J Manag Care Pharm. 2010;16(6 Suppl):S3-S20. Available at: http://amcp.org/WorkArea/ DownloadAsset. aspx?id=8359.

6. Hassol A, Shoemaker S. Exploratory research on medication therapy management. Final report. Contract HHSM-2005-000181/TO\#3. Centers for Medicare and Medicaid Services. July 8, 2008. Available at: http://www.cms. gov/Research-Statistics-Data-and-Systems/Statistics-Trends-and-Reports/ Reports/downloads/Blackwell.pdf. Accessed August 19, 2013.

7. Winston S, Lin YS. Impact on drug cost and use of Medicare Part D of medication therapy management services delivered in 2007. J Am Pharm Assoc (2003). 2009;49(6):813-20.

8. Fox D, Ried D, Klein G, et al. A medication therapy management program's impact on low density lipoprotein cholesterol goal attainment in Medicare Part D patients with diabetes. J Am Pharm Assoc (2003). 2009;49(2):192-99.

9. Welch EK, Delate T, Chester EA, Stubbings T. Assessment of the impact of medication therapy management delivered to home-based Medicare beneficiaries. Ann Pharmacother. 2009;43(4):603-10.

10. Centers for Medicare and Medicaid Services. CY 2013 medication therapy management program guidance and submission instructions. Part D sponsor letter, April 10, 2012. Available at: http://www.cms.gov/Medicare/ Prescription-Drug-Coverage/PrescriptionDrugCovGenIn/Downloads/MemoContract-Year-2013-Medication-Therapy-Management-MTM-ProgramSubmission-v041012.pdf. Accessed August 19, 2013.

11. Rucker NL. Medicare Part D's medication therapy management: shifting from neutral to drive. Insight on the Issues. June 2012. AARP Public Policy Institute. Available at: http://www.aarp.org/content/dam/aarp/research/public_policy_institute/health/medicare-part-d-shifting-from-neutral-to-driveinsight-AARP-ppi-health.pdf. Accessed August 19, 2013.

12. Centers for Medicare and Medicaid Services. 2011 Medicare Part D medication therapy management (MTM) programs. Fact sheet. June 30, 2011. Available at: http://www.cms.gov/Medicare/Prescription-Drug-Coverage/ PrescriptionDrugCovContra/Downloads/MTMFactSheet2011063011Final. pdf. Accessed August 19, 2013.

13. Balkrishnan R, Rajagopalan R, Camacho FT, et al. Predictors of medication adherence and associated health care costs in an older population with type 2 diabetes mellitus: a longitudinal cohort study. Clin Ther. 2003:25(11):2958-71.

14. World Health Organization. Adherence to long-term therapies: evidence for action. January 2003. Available at: http://www.who.int/chp/knowledge/ publications/adherence_report/en/index.html. Accessed August 19, 2013.

15. Gellad WF, Grenard JL, Marcum ZA. A systematic review of barriers to medication adherence in the elderly: looking beyond cost and regimen complexity. Am J Geriatr Pharmacother. 2011;9(1):11-23.

16. Claxton AJ, Cramer J, Pierce C. A systematic review of the associations between dose regimens and medication compliance. Clin Ther. 2001;23(8):1296-310

17. Chapman RH, Petrilla AA, Benner JS, et al. Predictors of adherence to concomitant antihypertensive and lipid-lowering medications in older adults: a retrospective cohort study. Drugs Aging. 2008;25(10):885-92.

18. Stoehr GP, Lu SY, Lavery L, et al. Factors associated with adherence to medication regimes in older primary care patients: the Steel Valley Seniors Survey. Am J Geriatr Pharmacother. 2008;6(5):255-63.
19. Gazmararian JA, Kripalani S, Miller MJ, et al. Factors associated with medication refill adherence in cardiovascular-related diseases: a focus on health literacy. J Gen Intern Med. 2006;21(12):1215-21.

20. Stuart, B, Simoni-Wastila, L. Final report: Monitoring chronic disease care and outcomes among elderly Medicare beneficiaries with chronic disease. Activity 3: Medication use and adherence among Medicare beneficiaries with diabetes and selected comorbidities enrolled in stand-alone Part D prescription drug plans. Medicare Research and Demonstration (MRAD) Contract HHSM-500-2005-000271. November 25, 2009. Available at: http:// www.cms.hhs.gov/Reports/Downloads/Stuart_MRAD_Final_Report_2009. pdf. Accessed August 19, 2013.

21. Grant RW, O'Leary KM, Weilburg JB, et al. Impact of concurrent medication use on statin adherence and refill persistence. Arch Intern Med. 2004;164(21):2343-48

22. Avalere Health. Avalere health insurance and reform experts analyze key trends in Medicare Advantage and Medicare Part D markets. 2012. Available at: http://www.avalerehealth.net/news/spotlight/medicare_advantage_and_ part_d_marketplace_2012/index.html. Accessed August 19, 2013.

23. Medical Economics. Red Book: Pharmacy's Fundamental Reference, 2009 Edition. New York: Thomson Reuters, 2009.

24. American Diabetes Association. Standards of medical care in diabetes-2008. Diabetes Care. 2008;31(Suppl 1):S12-S54.

25. Heart Failure Society of America, Lindenfeld J, Albert NM, et al. HFSA 2010 comprehensive heart failure practice guidelines. J Card Fail. 2010;16(6):el-194

26. Global Initiative for Chronic Obstructive Lung Disease (GOLD). Global strategy for diagnosis, management, and prevention of COPD. February 2013. Available at: http://www.goldcopd.org/guidelines-global-strategy-fordiagnosis-management.html. Accessed August 19, 2013.

27. Nau DP. Proportion of days covered (PDC) as a preferred method of measuring medication adherence. Pharmacy Quality Alliance. Available at: http://www.pqaalliance.org/images/uploads/files/PQA\%20PDC\%20vs\%20 \%20MPR.pdf. Accessed August 19, 2013.

28. Osterberg L, Blaschle T. Adherence to medication. N Engl J Med. 2005;353(5):487-97.

29. Centers for Medicare and Medicaid Services. Medicare Part D medication therapy management (MTM) programs: 2009 fact sheet. July 21, 2009. Available at: https://www.cms.gov/PrescriptionDrugCovContra/Downloads/ MTMFactSheet_2009_06-2009_fnl.pdf. Accessed August 19, 2013.

30. Mazzaglia G, Ambrosioni E, Alacqua M. Adherence to antihypertensive medications and cardiovascular morbidity among newly diagnosed hypertensive patients. Circulation. 2009;120(16):1598-605.

31. Stuart B. Where are the Medicare Part D claims data? Ann Intern Med. 2008;148(3):239-40.

32. Centers for Medicare and Medicaid Services. Advance notice of methodological changes for calendar year (CY) 2014 for Medicare Advantage (MA) capitation rates, Part C and Part D payment policies and 2014 call letter. February 15, 2013. Available at: http://www.cms.gov/Medicare/HealthPlans/MedicareAdvtgSpecRateStats/downloads/Advance2014.pdf. Accessed August 19, 2013.

33. Lichtenberg FR, Sun SX. The impact of Medicare Part D on prescription drug use by the elderly. Health Aff (Millwood). 2007;26(6):1735-44.

34. Yin W, Basu A, Zhang JX, Rabbani A, Meltzer DO, Alexander GC. The effect of the Medicare Part D prescription benefit on drug utilization and expenditures. Ann Intern Med. 2008;148(3):169-77.

35. Khan N, Kaestner R. Effect of prescription drug coverage on the elderly's use of prescription drugs. Inquiry. 2009;46(1):33-45. 